\title{
Submucosal tunneling endoscopic resection of a gastric lesion: a double-sided approach
}

In recent years, endoscopic procedures such as endoscopic full-thickness resection (EFTR) and submucosal tunneling endoscopic resection have been used to resect submucosal lesions [1]. Submucosal tunneling endoscopic resection is an adaption of both the peroral endoscopic myotomy and endoscopic submucosal dissection techniques. We present a case of a submucosal lesion resected using submucosal tunneling endoscopic resection with a double-sided approach. A 69-year-old woman was referred for a large submucosal gastric lesion $(8 \mathrm{~cm})$. The patient was not a surgical candidate because of pre-existing cardiopulmonary comorbidities. The patient underwent general anesthesia for the procedure. It was determined that EFTR would be risky due to lesion size. Thus, the decision was made to proceed with submucosal tunneling endoscopic resection ( $\triangleright$ Video 1 ). The gastric lesion was visualized in the fundus using a GIF-H180 endoscope (Olympus Corporation, Tokyo, Japan). A submucosal bleb was made with an injection needle filled with a saline and methylene blue solution. Afterwards, a mucosal incision was made in retroflexion using a HybridKnife (Erbe Elektromedizin, Tübingen, Germany) in order to create an opening for tunneling. The endoscope was advanced and continued submucosal dissection was performed with the HybridKnife to expose the lesion. Vessels were coagulated using the HybridKnife or a coagulation grasper (Olympus).

Due to large size of the lesion, tunneling from the opposing side was necessary ( Fig. 1) to allow for performing the remaining dissection. Subsequently, the lesion was resected en bloc; however, due to the size of the lesion, the removal was performed on two separate pieces with a snare and a Roth basket.

Finally, the defect was then closed with hemostatic clips. No adverse events oc-

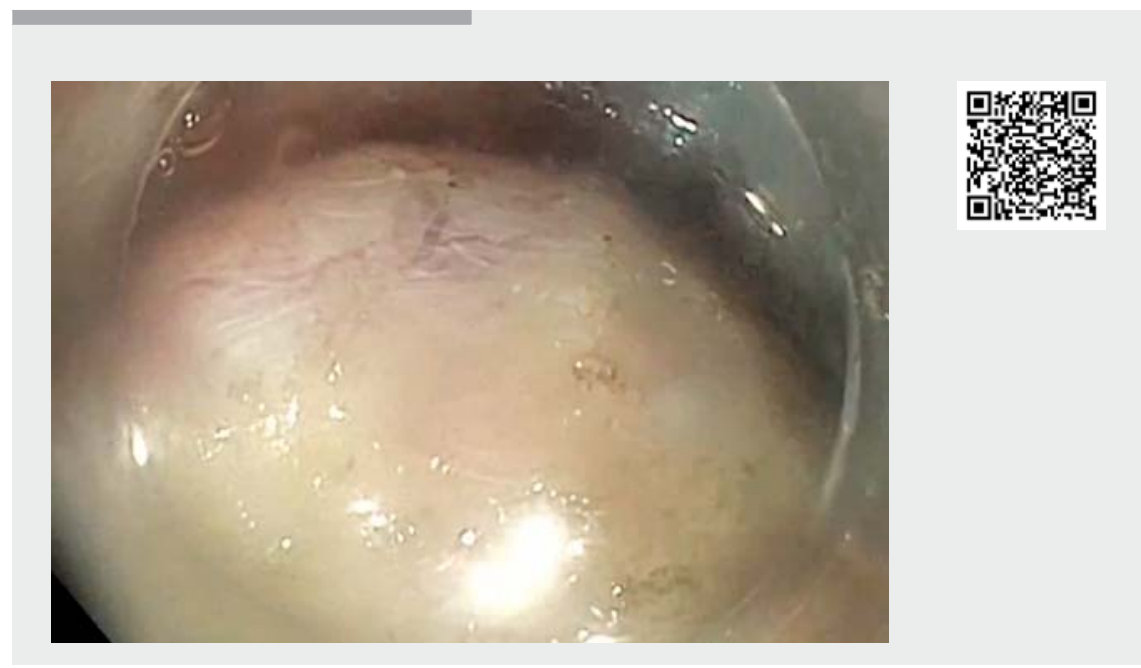

$\checkmark$ Video 1 Removal of a gastric lesion via the submucosal tunneling endoscopy resection technique.

curred. The patient was started on oral feeding early the next day and was discharged home. Histologic examination of the lesion revealed that the tumor was a completely resected leiomyoma. Submucosal tunneling endoscopic resection is an evolving technique for the resection of upper gastrointestinal submucosal tumors. It has advantages in maintaining gastrointestinal tract mucosal integrity [2]. In the present case, we successfully removed a large submucosal lesion using a double-sided technique of submucosal tunneling endoscopic resection. As far as we know, this is the first reported case that has used a double-sided approach to resect a lesion.

Endoscopy_UCTN_Code_TTT_1AO_2AG

\section{Competing interests}

Michel Kahaleh has received grant support from Boston Scientific, Fujinon, EMcison, Xlumena Inc., W.L. Gore, MaunaKea, Apollo Endosurgery, Cook Endoscopy, ASPIRE Bariatrics, GI Dynamics, NinePoint Medical, Merit

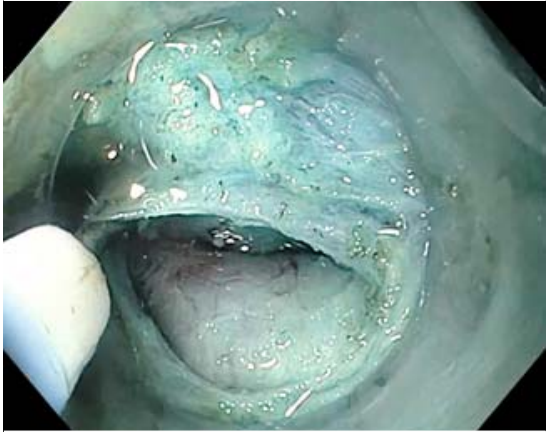

- Fig. 1 Endoscopic view of submucosal tunneling.

Medical, Olympus, and MI Tech. He is a consultant for Boston Scientific, Xlumena Inc., Concordia Laboratories Inc, ABBvie, and MaunaKea Tech. He is the CEO of Innovative Digestive Health Education \& Research Inc.

The authors

Ana Carbajo, Jordan Katz, Iman Andalib, Resheed Alkhiari, Michel Kahaleh Department of Gastroenterology, Robert Wood Johnson Medical Center, New Brunswick, New Jersey, USA 


\section{Corresponding author}

\section{Michel Kahaleh, MD}

Department of Gastroenterology,

Robert Wood Johnson University Hospital,

1 RWJ Place, MEB 464, New Brunswick,

NJ 08901, USA

Fax: +1-732-235-7307

mkahaleh@gmail.com

\section{References}

[1] Zhang X, Modayil R, Criscitelli T et al. Endoscopic resection for subepithelial lesions pure endoscopic full-thickness resection and submucosal tunneling endoscopic resection. Transl Gastroenterol Hepatol 2019; 4: 39
[2] Zhang Q, Wang F, Weig G et al. Endoscopic Resection of Gastric Submucosal Tumors: A Comparison of Endoscopic Nontunneling with Tunneling Resection and a Systematic Review. Saudi J Gastroenterol 2017; 23: $52-$ 59

Bibliography

DOI https://doi.org/10.1055/a-1089-7279

Published online: 29.1.2020

Endoscopy 2020; 52: E259-E260

(c) Georg Thieme Verlag KG

Stuttgart · New York

ISSN 0013-726X

\section{ENDOSCOPY E-VIDEOS}

https://eref.thieme.de/e-videos

回的 Endoscopy E-Videos is a free access online section, reporting 国: on interesting cases and new techniques in gastroenterological endoscopy. All papers include a high quality video and all contributions are freely accessible online.

This section has its own submission website at

https://mc.manuscriptcentral.com/e-videos 